\title{
Impact of Mental wellbeing and Quality of Life on Depression, Anxiety and Stress among people living with HIV/AIDS (PLWHA)
}

\author{
Bhavna Mukund ${ }^{1}$, Rejani Thudalikunil Gopalan ${ }^{2 *}$
}

\section{ABSTRACT}

Background: People living with HIV/AIDS (PLWHA) manifest a wide range of stress responses ranging from disbelief, denial, fear to extreme conditions of anxiety disorders, depression and even suicidal thoughts. These complications can have a significant impact on daily functioning and greatly diminish quality of life. Mental wellbeing and Quality of Life can help in better management of stress and facilitate adaptive coping among PLWHA. Aim: The research examined the impact of mental wellbeing and Quality of Life on Depression, Anxiety and Stress among people living with HIV/AIDS infection. Research Design: Cross sectional survey design was used. Sample: A sample of 60 people (males and females of equal number) over the age of 18 years and with the diagnosis for HIV/AIDS for more than six months participated in the study. Tools used: To assess the depression, anxiety and stress among PLWHA, DASS scale was used and to assess their psychological wellbeing, Warwick Edinburgh Mental Well-Being scale was used. In order to assess their present status of QOL regarding the illness, WHO's QOL HIVBREF Scale was used. Results: Majority of the PLWHA had moderate level of anxiety and mild level of depression after being diagnosed. Most of the participants have positive mental wellbeing and had enhanced quality of life. Conclusion: A direct effect of mental wellbeing has been found on the depression, anxiety and stress among PLWHA indicating that higher the mental wellbeing of the PLWHA, the greater is the likelihood that they do not suffer from depression, exhibit less anxiety and are living a stress free life and vice versa. The study also found direct impact of QOL on psychological distress, depression and anxiety among PLWHA i.e. poor QOL of PLWHA makes them more prone to and vulnerable to stress, depression and anxiety and vice versa.

Keywords: HIV/AIDS, Mental Well-Being, Quality of Life, Depression, Anxiety, Stress

The human immunodeficiency virus (HIV) is a retrovirus that infects cells of the immune system, destroying or impairing their function. As the infection progresses, the immune system becomes weaker, and the person becomes more susceptible to infections. The most advanced stage of HIV infection is acquired immunodeficiency syndrome (AIDS). It can take 10-15 years

\footnotetext{
${ }^{1}$ Clinical Psychologist

${ }^{2}$ Assistant Professor in Clinical Psychology, GFSU

*Corresponding Author

(C) 2015 I B Mukund, R Gopalan; licensee IJIP. This is an Open Access Research distributed under the terms of the Creative Commons Attribution License (http://creativecommons.org/licenses/by/2.0), which permits unrestricted use, distribution, and reproduction in any Medium, provided the original work is properly cited.
} 
for an HIV-infected person to develop AIDS; antiretroviral drugs can slow down the process even further. HIV is transmitted through unprotected sexual intercourse (anal or vaginal), transfusion of contaminated blood, sharing of contaminated needles, and between a mother and her infant during pregnancy, childbirth and breastfeeding (WHO, 2001).

\section{Mental Wellbeing}

Mental well-being or mental health is defined by WHO (2001) as a state of well-being in which every individual realizes his or her own potential, can cope with the normal stresses of life, can work productively and fruitfully, and is able to make a contribution to her or his community. Ryff's early work (Ryff, 1989a) identified aspects that constitute wellbeing: autonomy; environmental mastery; positive relationships with others; purpose in life; realisation of potential and self-acceptance. More recent research has placed different emphases on what wellbeing is: ability to fulfil goals (Foresight Mental Capital and Wellbeing Project, 2008); happiness (Pollard \& Lee, 2003) and life satisfaction (Diener \& Suh, 1997; Seligman, 2002a). Psychosocial wellbeing - which includes perceived positive relationships and a purpose in life, as well as environmental mastery - is important for older adults to age successfully. It can also have a positive impact on HIV prevention. (Golub S. et al. 2013).

Perceived awareness of overall general wellbeing tends to affect an individual's confidence in his/her health status which may have a negative effect on their daily activities and social participation thereby and can have an adverse impact on their psychological well-being. Selfappraised wellbeing is a subjective pointer of general wellbeing and has been found to have most grounded relationship with all the markers of mental well- being. Great self-appraised wellbeing could essentially decrease the perceived stress of PLWHA (Wei Sun, Ming Wu, Peng QU, Chumming Lu, Lie Wang, 2014).

\section{Quality of Life}

WHO defines quality of life as: an individual's perception of their position in life in the context of the culture and value systems in which they live and in relation to their goals, expectations, standards and concerns. It is a broad ranging concept affected in a complex way by the person's physical health, psychological state, personal beliefs, social relationships and their relationship to salient features of their environment (WHO, 1997). Several factors associated with better QOL among PLWHA have been reported in the international literature, and mainly, the impact of HIV on QOL are categorized into four major domains viz. physical, psychological, social and environmental. WHO (1998) and the Joint United Nations Programme on HIV/AIDS have proposed that improvement of quality of life should be one of the primary goals in providing care and support to PLWHA (UNAIDS, 2014).

\section{HIV/AIDS: Depression, Anxiety and Stress}

Depression is a serious medical condition that can be paralyzing to sufferers. It is twice as common in PLWHA as in general population (Leserman,2008). Depression is characterized by 
the presence of most or all of the following symptoms: low mood, apathy, fatigue, inability to concentrate, loss of pleasure in activities, changes in appetite and weight, trouble sleeping, low self-worth, and, possibly, thoughts of suicide (Leserman, 2008). In a study conducted in Nigeria (Shittu, Alabi, Odeigah, Sanni et al. 2014,). The prevalence of depression among the HIV/AIDS patient was $56.7 \%$. Twenty nine (17.1\%) were hopeless, twenty eight (16.5\%) had at one time or the other thought of taking their lives, six (3.5\%) had plan to take their lives. The significant correlations between hopelessness, depression and suicidal ideation are important markers that should alert clinicians to underlying suicide risk in HIV positive patients (Comer, 1995).

Anxiety is a feeling of panic or apprehension, which is often accompanied by the physical symptoms of sweating, shortness of breath, rapid heartbeat, agitation, nervousness, headaches, and panic (APA, 2000). Anxiety can accompany depression or be seen as a disorder by itself, often caused by circumstances that result in fear, uncertainty, or insecurity (Gonzalez, Zvolensky, Parent, Grover, Hickey, 2012). Especially among those that have recently been diagnosed with HIV, anxiety has been shown to be more predominant among patients with stress or excess social stigma related to their diagnosis. It has been observed that anxiety can also correlate with lower adherence to antiretroviral therapy (ART) and medical recommendations (Morrison et al., 2011).

Clinicians treating PLWHA have long accepted the notion that stress affects immune function. Indeed, this belief is nearly as old as the epidemic itself: counselling patients to reduce the number of stressors in their life has been standard advice since the days when the acquired immunodeficiency syndrome was known. It remains good advice-and we now have scores of studies which show that stress has an invidious impact on immune function. Further, stress also adversely affects mental well-being and QOL and vice versa. A study in China had reported that, due to serious psychological stress, $40.1 \%$ of PLWHA had contemplated taking requital on other individuals or society, which appeared to relate to a potential threat to spread HIV/AIDS. Therefore the mental well-being of PLWHA should be a principal focus of health care provided for PLWHA regardless of the epidemic characteristics (Wei Sun, Ming Wu, Peng QU, Chumming Lu, Lie Wang, 2014).

Sowell et al. (1997) conducted a longitudinal study with a sample of 263 HIV infected women from eight public health HIV/AIDS clinics serving both rural and urban areas in the state of Georgia in the US. Social factors (disclosure and material resources), psychological factors (fatalism, stigma, emotional distress and intrusion) were found to be important determinants of quality if life. Limited functioning was associated with fatalism, employment status and stage of disease (as cited in Phaladze et al. 2002).

Sibnath (2002) had undertaken a study in India to explore the psychological dispositions of 32 HIV and 12 AIDS patients through an in-depth interview guide. His findings revealed that guilt feelings, anxiety and fear were more evident amongst most of the patients, followed by feelings 
of hopelessness, depression and severe withdrawal. Most patients did not disclose their HIV status and hence social support did seem to be strong for them. Ten per cent of the patients had expressed suicidal ideation (Nair, 2008).

Perry, Jacobsberg and Fishman (1990) had reported that suicidal ideation in HIV seropositive patients was primarily a function of concomitant depression. Hopelessness was a key variable that linked depression to suicide. Past behaviour, multiple bereavements, isolation from family and friends and hopelessness were common factors of guilt resulting in many AIDS-related suicides.

While talking about the circumstances that influence their psychological adjustment and their reduced ability to cope with the disease, it is worth mentioning that from the early detection of the disease, the most common responses by people living with PLWHA include a wide range of psychological disturbances such as mild pathologic apathy, shock, disbelief, denial, fear, anxiety, and helplessness to extreme conditions of anxiety disorders, depression and even suicidal thoughts (Treisman, Angelino, Hutton. 2001). They worry about health deterioration and a shortened life span. Therefore, a strong sense of foreshortened future and despair is common. Among PLWHA, more direct engagement with and acceptance of HIV illness were associated with better adjustment to living with the condition and greater reduction in levels of stress (Koopman et al., 2000; Turner-Cobb et al., 2002).

Research shows that psychological, psychosocial and psychiatric factors play a significant role in how well PLWHA comply with treatment. According to Singh et al. (2005), variables like satisfaction with social support and ability to cope significantly correlate with treatment adherence, while dimensions like hopelessness, loss of motivation and poor coping skills are indicative of noncompliance The quality of life becomes a critical area of concern for patients, health care providers, psychological and social support providers (Solomon et al. 2009).

Many studies have shown that HIV leads to a general decline in mental health and quality of life. Patients with HIV are faced with numerous psychological and biological problems which make them different from other people (Jonson et al., 2013). Not many Indian studies were conducted on HIV/AIDS on these dimensions. Hence the present study attempted to explore the impact of mental well-being and QOL on depression, anxiety and stress among PLWHA.

\section{METHODOLOGY}

The study aims to find the impact of mental well-being and quality of life on Depression, Anxiety and Stress among PLWHA. Cross sectional design was used in the study. A purposive sample of 60 people diagnosed with HIV/AIDS (30 males and 30 females) has been taken, and data was collected from a non-government organization (NGO) situated in Lucknow. PLWHA (with a confirmed medical diagnosis) above 18 years of age only were included in the study. The Exclusion Criteria included presence of any co-morbid psychiatric illness/neurological trauma or brain disease/mental retardation. 


\section{Tools Used:}

Demographic sheet: Demographic details (including period taken for confirmation of diagnosis) of PLWHA were noted with their mode of infection (sexual contact, blood transfusion and drug injection).

Depression Anxiety Stress Scale (DASS): (Lovibond \& Lovibond, 1995): The DASS is a 42-item questionnaire which includes three self-report scales intended to measure the negative emotional states of depression, anxiety and stress. Each of the three scales contains 14 items, divided into subscales of 2-5 items with similar content. Respondents are asked to use 4-point severity/frequency scales to rate the extent to which they have experienced each state over the past week. Scores of Depression, Anxiety and Stress are calculated by summing the scores for the relevant items. The depression, anxiety and stress scale has 14 items each with scores evaluated as per the severity-rating i.e.0-28+ depression, 0-20+anxiety, 0-34+ stress. Wherein score of more than 28 suggests severe depression, more than 20 shows severe anxiety and more than 34 shows severe stress. The internal consistency (i.e. Cronbach's alpha) of each scale of the DASS was quite favourable ( $\sim=0.96,0.89$ and 0.93 for Depression, Anxiety, and Stress, respectively) Construct validity was supported by moderately high correlations of the DASS with indices of convergent validity (0.65 and 0.75), and lower correlations of the DASS with indices of divergent validity (range -0.22 to 0.07 ).

Warwick-Edinburgh Mental Well-being Scale (WEMWBS) (Tennant et al. 2007). It measures positive mental health. WEMWBS is a 14-item scale; each answered on a 1 to 5 Likert scale. Items cover different aspects of eudemonic and hedonic mental wellbeing and are worded positively. Item scores are summed to produce a total score ranging from a minimum of 14 to a maximum of 70 with higher scores representing higher levels of mental well-being. Test retest reliability was found to be high (0.83) and WEMWBS showed good content validity.

WHO QOL HIV BREF (WHO Field Centre for the Study of QOL of Bath, 2008) is a module specifically designed for people with HIV or AIDS HIV BREF, a newly-developed, multi-dimensional instrument comprising 31 items designed to assess the QOL of people infected with human immunodeficiency virus (HIV). WHOQOL-HIV evaluates the QOL from six domains and 29 facets. Responses to the items were scored from 1 (least favourable condition) to 5 (most favourable condition), with the domain scores, ranging from 4 to 20, being calculated by multiplying the average scores for all items in the domain by 4. A higher score would indicate a better QOL on the corresponding domain. It is found to have internal consistency (Cronbach’s alpha) ranged between 0.67 and 0.80 across the six domains.

\section{Procedure:}

After obtaining informed consent from the authorities of a NGO and the ethical approval of the concerned bodies; participants were informed about the study and the associated confidentiality. Participants were clearly explained that they could discontinue their participation if they felt 
uncomfortable at any point of time during the assessment. Informed consent was taken from the participants, and the tools were administered individually. Data was entered on the SPSS version 20 and was analysed by using appropriate statistical procedures.

\section{RESULTS}

The results were obtained by analysis on SPSS version 20. The techniques used were Multiple regression analysis, Mean and Standard deviation.

The demographic data ( Table 1) shows that maximum participants were in their young adulthood, aged between 20-29 years, $\mathrm{N}=31$, (51.7\%) and equal number of male and female participants (Male $=30$, female $=30$ ) were engaged for the study. Among the participants most of them were married ( $\mathrm{N}=35$, (58.3\%), and had education up to secondary level, $\mathrm{N}=29,(48.3 \%)$. From the demographic sheets, it is observed that maximum number of participants are engaged in private jobs, $\mathrm{N}=22$, (36.7\%) and they belong to middle socio economic status (SES), $\mathrm{N}=26$ (43.3\%) with an annual income of Rs.20,041 to Rs.33,240 and were settled in urban areas as their domicile, $\mathrm{N}=30(50 \%)$. Most participants had contracted HIV/AIDS through sexual intercourse, $\mathrm{N}=35$ (58.3\%) with their partners (from their husband \& girlfriends) and had conceded to their illness within three to four years of contact, $(\mathrm{N}=73.2 \%$, with an average onset in the year $2012(M=2012.08, S D=2.250)$.

Table 1, Socio-demographic details of the sample.

\begin{tabular}{|c|c|c|c|}
\hline Variables & Sub variables & Frequency & Percentage \\
\hline \multirow{5}{*}{$\begin{array}{l}\text { Income/Socio economic status } \\
\text { (SES) }\end{array}$} & Less than 10,032 p.a (BPL) & 7 & $11.7 \%$ \\
\hline & $\begin{array}{l}\text { 10,033 to } 20,040 \\
\text { p.a. (low middle class) }\end{array}$ & 19 & $31.7 \%$ \\
\hline & $\begin{array}{l}33,241 \text { to } 33,240 \\
\text { p.a. (middle class) }\end{array}$ & 26 & $43.3 \%$ \\
\hline & $\begin{array}{l}33,241 \text { to } 66,840 \\
\text { p.a. (upper middle class) }\end{array}$ & 6 & $10.0 \%$ \\
\hline & $\begin{array}{l}\text { Above 66,840 p.a. ( upper } \\
\text { class) }\end{array}$ & 2 & $3.3 \%$ \\
\hline \multirow[t]{3}{*}{ Domicile } & Urban & $30 \%$ & $50 \%$ \\
\hline & Rural & 6 & $100 \%$ \\
\hline & Semi-Urban & 24 & $40 \%$ \\
\hline \multirow[t]{3}{*}{ Onset } & $1-4$ & 44 & $73.2 \%$ \\
\hline & $5-8$ & 13 & $21.75 \%$ \\
\hline & $9-11$ & 3 & $5.1 \%$ \\
\hline \multirow[t]{3}{*}{ Mode of infection } & Sexual Partner & 35 & $58.3 \%$ \\
\hline & Blood Transfusion & 10 & $16.3 \%$ \\
\hline & Drug Injection & 15 & $25 \%$ \\
\hline
\end{tabular}


Table 2, Mean and Standard Deviation (SD) of variables undertaken in the study.

\begin{tabular}{|l|l|l|l|}
\hline Variables Used & Mean & $\begin{array}{l}\text { Standard } \\
\text { Deviation }\end{array}$ & Total N \\
\hline Depression & 13.43 & 7.277 & 60 \\
\hline Anxiety & 14.23 & 8.018 & 60 \\
\hline Stress & 14.25 & 5.748 & 60 \\
\hline Mental Well Being & 45.10 & 8.889 & 60 \\
\hline QOL Physical & 7.40 & 1.532 & 60 \\
\hline QOL Psychological & 7.78 & 2.051 & 60 \\
\hline QOL Social relations & 12.40 & 4.537 & 60 \\
\hline QOL Environment & 7.60 & 2.149 & 60 \\
\hline
\end{tabular}

Mean analysis of the clinical variables in table 2 indicates that on Depression, anxiety and stress scale, majority of the participants had moderate level of anxiety $(M=14.23, S D=8.0818)$ and mild level of depression after being diagnosed positive with HIV/AIDS ( $M=13.43$ \&SD= 7.277). No severe depression and stress has been found in the present study among PLWHA. It is found that majority of the participants have positive mental well-being ( $M=45.10$ \& SD=8.889) which indicates that they are optimistic about overcoming their illness. The mean analysis trend shows that the participants had enhanced quality of life in terms of social relationships $(\mathrm{M}=12.40$ \& $\mathrm{SD}=4.537)$ indicating that the participants wished to strive for and maintained cordial social relationships with most others in their life.

All the variables were enlisted and data was transferred in SPSS version 20. Variable were analysed for descriptive statistics and correlations (Pearson's coefficient) (see Table 2). All The variables were also tested for the normal distribution using Shapiro-Wilk’s test.

Multiple Stepwise Regression analysis was used to understand the cause effect relationship among depression, anxiety and stress with mental wellbeing and quality of life (QOL). F test was used to remove variables in stepwise regression $(\mathrm{p}<0.05)$. $\mathrm{R}$ square values were used in order to understand the importance of significant independent variable in selected regression models. Residual analysis was performed to validate the regression model. Variables like Depression, Anxiety and Stress were used as dependent variables and those under mental wellbeing and quality of life were used as independent variables. (see Table 3) 

with HIV/AIDS (PLWHA)

Table 3, Summary of Multiple Regression Models Analysis

\begin{tabular}{|c|c|c|c|c|c|c|}
\hline Independent & Dependent & Model Summary & & & & \\
\hline $\begin{array}{l}\text { Mental Well Being } \\
\text { (MWB) And }\end{array}$ & & $\begin{array}{l}\text { Significant } \\
\text { Variables }\end{array}$ & $\begin{array}{l}\mathrm{F} \\
\text { change }\end{array}$ & $\begin{array}{l}\text { Sig. } \\
\text { Value } \\
\text { Change } \\
\mathrm{p}<.05\end{array}$ & $\begin{array}{l}\text { Adjusted } \\
\text { R square } \\
\text { value }\end{array}$ & $\begin{array}{l}\text { Effect of } \\
\text { significant } \\
\text { Variable/s }\end{array}$ \\
\hline $\begin{array}{l}\text { Quality of Life } \\
\text { (QOL) }\end{array}$ & & $\begin{array}{l}\text { Mental Well } \\
\text { Being }\end{array}$ & 3.199 & .079 & 0.36 & $\begin{array}{l}\text { Negative } \\
\text { Effect }\end{array}$ \\
\hline Dimensions & Depression & QOL Physical & 6.826 & .011 & 0.90 & $\begin{array}{l}\text { Negative } \\
\text { Effect }\end{array}$ \\
\hline 2a:QOL Physical & & $\begin{array}{l}\text { QOL } \\
\text { Psychological }\end{array}$ & 2.938 & .092 & .032 & $\begin{array}{l}\text { Negative } \\
\text { Effect }\end{array}$ \\
\hline $\begin{array}{l}\text { 2b:QOL } \\
\text { Psychological }\end{array}$ & & $\begin{array}{l}\text { QOL } \\
\text { Soc.relations. }\end{array}$ & 8.527 & .005 & .113 & $\begin{array}{l}\text { Negative } \\
\text { Effect }\end{array}$ \\
\hline 2c:QOL Social & & $\begin{array}{l}\text { QOL } \\
\text { Environment }\end{array}$ & 3.723 & .059 & .044 & $\begin{array}{l}\text { Negative } \\
\text { Effect }\end{array}$ \\
\hline Relations & & $\begin{array}{ll}\text { Mental Well } & \text { Weing }\end{array}$ & 1.764 & .189 & .013 & $\begin{array}{l}\text { Negative } \\
\text { Effect }\end{array}$ \\
\hline $\begin{array}{l}\text { 2d:QOL } \\
\text { Environment }\end{array}$ & Anxiety & QOL Physical & 6.538 & .013 & .086 & $\begin{array}{l}\text { Negative } \\
\text { Effect }\end{array}$ \\
\hline & & $\begin{array}{l}\text { QOL } \\
\text { Psychological }\end{array}$ & 11.382 & .001 & .150 & $\begin{array}{l}\text { Negative } \\
\text { Effect }\end{array}$ \\
\hline & & $\begin{array}{l}\text { QOL } \\
\text { Soc.relations }\end{array}$ & 21.422 & .000 & .257 & $\begin{array}{l}\text { Negative } \\
\text { Effect }\end{array}$ \\
\hline & & $\begin{array}{l}\text { Mental Well } \\
\text { Being }\end{array}$ & 2.258 & .138 & .021 & $\begin{array}{l}\text { Negative } \\
\text { Effect }\end{array}$ \\
\hline & Stress & QOL Physical & 4.544 & .037 & .057 & $\begin{array}{l}\text { Negative } \\
\text { Effect }\end{array}$ \\
\hline & & $\begin{array}{l}\text { QOL } \\
\text { Psychological }\end{array}$ & 6.497 & .013 & .085 & $\begin{array}{l}\text { Negative } \\
\text { Effect }\end{array}$ \\
\hline & & $\begin{array}{l}\text { QOL } \\
\text { Soc.relations }\end{array}$ & 8.287 & .006 & .110 & $\begin{array}{l}\text { Negative } \\
\text { Effect }\end{array}$ \\
\hline & & $\begin{array}{l}\text { QOL } \\
\text { Environment }\end{array}$ & 1.730 & .194 & .012 & $\begin{array}{l}\text { Negative } \\
\text { Effect }\end{array}$ \\
\hline
\end{tabular}

Impact of mental wellbeing on depression, anxiety and stress. From table 3, it is observed that mental wellbeing has a negative effect on depression, stress and anxiety. The multiple 
regression values show that as the value of mental wellbeing increases, the values for depression $(\mathrm{r}=0.36, \mathrm{p}=.079)$, stress $(\mathrm{r}=.021, \mathrm{p}=.138)$ and anxiety $(\mathrm{r}=.013, \mathrm{p}=.189)$ decrease. This implies that higher the mental wellbeing of the PLWHA, the greater is the likelihood that they do not suffer from depression, exhibit less anxiety and are living a stress free life and vice versa.

\section{Impact of QOL on Depression, Anxiety and Stress}

Similarly the multiple regression analysis revealed that all the four dimensions of quality of life too have a negative impact on the depression, anxiety and stress. The study found that greater the physical, psychological, social relationships and environment aspects of the QOL of PLWHA, lesser would be their depression, stress and anxiety (See table 3). Overall it seems that social relationships and environmental aspects of quality of life is the most important independent variable among the tested variable as the explanatory variable of models tested.

\section{DISCUSSION}

\section{Socio-Demographic Details}

The study undertaken shows that majority PLWHA are in their young adulthood, aged between 20-29 years, $\mathrm{N}=31$, (51.7\%) This is consistent with the findings that people aged between 15 to 24 years were vulnerable to HIV, while those in their 30s were most susceptible (Khan et al. 2008 and Mini, Ramesh, Parthasarathi, Mothi, Swamy, 2012). Equal number of male and female participants $($ Male $=30$, Female $=30$ ) were included for the research. Among the participants most of them were married $(\mathrm{N}=35$, $(58.3 \%)$.

From table 1, it is observed that majority if participants had education up to secondary level, $\mathrm{N}=$ 29, (48.3\%). Maximum number of participants was engaged in private jobs, $\mathrm{N}=22$, (36.7\%), and they belong to middle socio economic status, $\mathrm{N}=26$ (43.3\%) with an annual income of Rs.20,041 to Rs.33,240. A lack of socioeconomic resources is linked to the practice of riskier health behaviours, which can lead to the contraction of HIV. These behaviours include earlier initiation of sexual activity and less frequent use of condoms (Adler, 2006). Quality of life can be influenced by educational status and income as well (Wig, Lekshmi, Pal, Ahuja, Mittal, Agarwal. 2006). Furthermore, SES is a key factor in determining the QOL for individuals after they are affected by the virus. Those with fewer resources are often left with limited treatment options. This is also in consonance with our study, wherein the majority of the participants are not highly educated and have private jobs with low income. It is noticed that majority of people were settled in urban areas as their domicile, $\mathrm{N}=30$ (50\%). In sub-Saharan Africa, the HIV/AIDS epidemic has historically concentrated in urban areas, where significantly higher HIV prevalence rates have been recorded than in rural areas (Thomas and Crewe, 2000).

Most participants had contracted HIV/AIDS through sexual intercourse, N=35 (58.3\%) with their partners (husband \& girlfriends) but most of them took almost three to four years to seek medical treatment and counselling, $(\mathrm{N}=(73.2 \%)$. The predominant risk behaviour among psychiatric 
patients in India is unprotected heterosexual intercourse, which reflects the common mode of transmission in the country (Jayarajan, Chandra. 2010).

\section{Effect of mental wellbeing on depression, anxiety and stress among PLWHA}

The study revealed that mental wellbeing is related to depression, wherein poor mental wellbeing leads to depression $(\mathrm{r}=0.36, \mathrm{p}=.079)$ in PLWHA.

Professor Sherr highlighted studies which show that people who are depressed are at greater risk of HIV infection in the first place. The available evidence demonstrates that people with depression are less likely to adhere to their HIV treatment; it also shows that depression can (independent of adherence) impact on disease progression, as poor mental health has been shown to increase the rate of immunological decline, so make their condition deteriorate faster than it would otherwise. In addition to negative mental health, there is a particular dearth of research on the effect of positive mental health on general well-being. Their recent UK study found that a high proportion of people living with HIV reported a range of symptoms and impacts which resulted from the psychological burden of living with HIV; these included lack of energy, difficulty concentrating, feeling irritable and nervous (Sherr L et al 2007).The study has found that mental wellbeing has a negative impact on anxiety ( $\mathrm{r}=0.013, \mathrm{p}=.189)$ among PLWHA. Negative mental wellbeing leads to increase in anxiety symptoms. Similar studies have found that many PLWHIV/AIDS can expect to experience depression and/or anxiety at different points in their lives. They show that depression is under-recognized in PLWHIV/AIDS, with less than $10 \%$ receiving treatment for their mental illness. They also show depression as a factor affecting adherence to HIV treatment (Starace, Ammassari, Trotta et al, 2007).

The study found that poor mental wellbeing tends to increase vulnerability to stress ( $\mathrm{f}=.021$, $\mathrm{p}=.138$ ) among PLWHA. Some evidence suggests that an accumulation of negative life events over several years of follow-up predicts worse AIDS related outcomes. For example, among HIV-positive men, each additional moderately severe event increased the risk of progressing to AIDS by $50 \%$ and of developing an AIDS related clinical condition by 2.5-fold. Moreover, stress has been found to influence the course of virally initiated illnesses to which persons with HIV are especially susceptible. (Cohen, Kessler \&Gordon, 1995)

\section{Effect of Quality of life on depression, anxiety and stress among PLWHA}

In the present study, signs of depression, anxiety and stress were related to lower scores in all domains of quality of life. It is noted that that a poor physical aspect of QOL $(r=0.90, p=.011)$ leads to increase in depressive, anxiety $(\mathrm{r}=.086, \mathrm{p}=.013)$ and stress $(\mathrm{r}=.057, \mathrm{p}=.037)$ symptoms among PLWHA and vice versa. The study indicates that a healthier physical self, minimizes the risks of distress, harbouring depressive tendencies and getting overwhelmed or anxious. Depression, anxiety and anger are emotions that sometimes coexist with physical illness, and may affect the individuals' functional performance, symptom, health perceptions and quality of life (Anderson, 1995; Moody, McCormick \& Williams, 1990). 
Many people living with HIV/AIDS find it challenging to attend to daily tasks of living, participate in moderate to vigorous physical activities or have sufficient energy and vitality to engage in an active social life while managing HIV/AIDS. Fatigue and low energy have been associated with both physical and psychological morbidity (Breitbart, Mc Donald, Rosenfeld, Monkman, Passik 1998) and poor QOL Zinkermagel, Ledergerber, Battegay, Cone, Vernazza, Hirschel 1999) in persons living with HIV/AIDS.

The study revealed that participants with impaired psychological aspects of quality of life tend to show greater anxiety $(\mathrm{r}=.150, \mathrm{p}=.001)$ and $\operatorname{stress}(\mathrm{r}=.085, \mathrm{p}=.013)$ and vice versa. On psychological aspect of QOL, the study suggests that participants having self-realization of their potential, positive thinking, striving to find meaning in life, being emotionally stable in arduous circumstances and having ability to take decisions tend to reduce anxiety and stress and vice versa. Not many studies have been conducted on aforesaid factors. However, Nilsson Schönnesson and Ross (1989) had found in their study that existential issues invariably emerged in response to threats to physical and psychological survival. Applying this view among PLWHA, their sense of meaning of life may beshattered, and they would need to reconstruct new meanings that incorporate HIV and allies issues, and one can safely conclude that, factors enhancing quality of life would lead to reduction in stress and anxiety.

The study found that poor social relationships (QOL) tend to negatively affect the mental health of the PLWHA. This has a negative impact on depression ( $r=.113, p=.005)$ anxiety $(\mathrm{r}=.257, \mathrm{p}=.000)$ and $\operatorname{stress}(\mathrm{r}=.110, \mathrm{p}=.006)$.In addition, poor social functioning may be associated with greater use of avoidance coping strategies such as withdrawal and conflictual social interactions. Social isolation and conflictual social interactions have been shown to increase stress, resulting in poorer overall social functioning.(Nathabiseng et al 2005)

The study revealed that poor environmental aspect of quality of life too has a negative impact on depression $(\mathrm{r}=.044, \mathrm{p}=.059)$ and stress $(\mathrm{r}=.012, \mathrm{p}=.194)$ The more detrimental and hazardous is the environmental quality of PLWHA, the more they tend to experience depression and stress. Not having a stable relationship was associated with poorer quality of life in the social relationships and environment domains, which is consistent with other results reported in the literature (Passos\& Souza,2015).

Therefore the higher QOL of PLWHA in their physical, psychological aspects, maintaining positive social relationships and enriching environment would help them to overcome their illness and reduction in depression, anxiety and stress is observed and vice versa.

\section{CONCLUSION}

The aim of the study was to study the impact of mental well-being and QOL on depression, anxiety and stress among PLWHA. A direct effect of mental wellbeing has been found on the depression, anxiety and stress among PLWHA indicating that poor mental wellbeing would lead to psychological distress and may result into disorders like depression and anxiety and vice 
versa. Majority of PLWHA, who had negative well-being, exhibit the above symptoms. The study also found direct impact of QOL on psychological distress, depression and anxiety among PLWHA i.e. poor QOL of PLWHA makes them more prone to and vulnerable to stress, depression and anxiety and vice versa.

\section{Limitation:}

From the limitations, the study involved only 60 participants, which needs to be broadened to arrive at a more conclusive relationship between mental wellbeing and QOL with depression, anxiety and stress among PLWHA. Also, in order to protect the privacy of PLWHA, it was not possible to collect detailed data in relation to antiretroviral therapy.

\section{Implications of the Study:}

Appropriate interventional strategy need to be addressed for improving mental wellbeing and QOL and alleviate depression, anxiety and stress among PLWHA so as to help them develop better coping strategy to deal with the disease and associated problems.

\section{REFERENCES}

Adler, N. E. (2006). Overview of health disparities. In G. E. Thompson, F. Mitchell, \& M. Williams (Eds.), Examining the health disparities research plan of the National Institutes of Health: Unfinished business. 2006. (pp. 129-188)

Bakiono et al.(2014).Quality of life in people living with HIV: Cross-sectional study in Ouagadouuou, Burkina Faso. Springer Plus. 3.372. http://www. springerplus.com/ content/3/1/372

Breitbart, W., McDonald, M. V., Rosenfeld, B., Monkman, N. D., Passik, S. (1998). Fatigue in ambulatory AIDS patients. Journal of pain and symptom management;15:159-67.

Cohen S, Kessler RC, Gordon UL. Strategies for measuring stress in studies of psychiatric and physical disorder. In: Cohen S, Kessler RC, Gordon UL, eds. Measuring Stress: A Guide for Health and Social Scientists. New York, NY: Oxford University Press; 1995:3-26.

Comer, R. I. (1995).Abnormal Psychology. NewYork : Freeman and Company

Development of the World Health Organization WHOQOL-BREF quality of life assessment. The WHOQOL Group. Psychological Medicine. 1998; 28:551-8.25.

Golub, S., Botsko.M., Gamarel, K. et al. (2013). Dimensions of psychological well-being predict consistent condom use among older adults living with HIV. Journal of Ageing International; 38:179-194.

Gonzalez, A., Zvolensky, M. J., Parent, J., Grover, K. W., Hickey, M. (2012).HIV symptom distress and anxiety sensitivity in relation to panic, social anxiety, and depression symptoms among HIV-positive adults. AIDS Patient Care and STDs (epub) 2012 (Jan 16).

Jayarajan, N., Chandra, P. S. (2010). HIV and mental health: An overview of research from India. Indian Journal of Psychiatry 2010;52:S269-73.42.

Khan, S., Mishra, V. (2008). Youth Reproductive and Sexual Health: DHS Comparative. Calverton, MD: Macro International, 2008.

Mini, K. V., Ramesh, A., Parthasarathi, G., Mothi, S. N., Swamy, V. T. (2012). Impact of pharmacist provided education on medication adherence behaviour in HIV/AIDS patients 
treated at a non-government secondary care hospital in India. Journal of AIDS and HIV Research 2012; 4(4):94-99.

Nathabiseng et al 2005, Quality of life and concept of living well with HIV/AIDS in sub saharan Africa, journal of noursing scholarship, 2005, 37:2, sigma theta tau international

Perry, M. J. (1998). Gender, race and economic perspectives on the social epidemiology of HIV infection: Implications for prevention. Journal of Primary Prevention, 19, 97-104.

Phaladze et al. (2002). Quality of life and concept of living well with HIV/AIDS in sub Saharan Africa. Journal of nursing scholarship 2005;37(2):120-6.

Sherr L et al (2007), 'Successive switching of antiretroviral therapy is associated with high psychological and physical burden’, International Journal of STD \& AIDS, Oct; 18(10):700-4

Shittu, R.O., Alabi, M.K., Odeigah, L.O., Sanni, M.A., Issa, B.A., Olanrewaju, A.T., Sule, A.G. and Aderibigbe, S.A. (2014) Suicidal Ideation among Depressed People Living with HIV/AIDS in Nigeria, West Africa. Open Journal of Medical Psychology, 3, 262-270.

Solomon, G.F., Kemeny, M. E., Temoshok, L. Psycho-neuro-immunologic aspects of human immunodeficiency virus infection, in Psychoneuroimmunology, Ader, R., Felton, D. L., and Cohen, N., Eds. Academic Press, San Diego, 1991).

Starace F, Ammassari A, Trotta MP, et al. Depression is a risk factor for suboptimal adherence to highly active anti retroviral therapy. Journal of Acquired Immune Deficiency Syndrome.2002;31(Suppl 3):S136-S139.

Susane Müller Klug Passos, Luciano Dias de Mattos Souza. An evaluation of quality of life and its determinants among people living with HIV/AIDS from Southern Brazil. Cad.SaúdePública vol.31 no.4 Rio de Janeiro Apr. 2015ISSN 0102-311X102.

Thomas, E. and Crewe, M. (2000), 'Local Authority Responses to HIV/AIDS: An Overview of a Few Key Cities”, Urban Health and Development Bulletin, Vol 8 No 2, 9-30.

Treisman, G. J., Angelino, A. F., Hutton, H. E. (2001). Psychiatric issues in the management of patients with HIV infection. Journal of American Medical Association JAMA.2001; 286:2857-64.

UNAIDS, World Bank. (2008). Uganda Methods of Transmission Study: National Synthesis Results and Policy and Programme Implications, Presented at the International AIDS Conference, Mexico City, August 3-8, 2008.

WeiSun, Ming Wu, Peng QU, Chumming Lu, Lie Wang. (2014). Psychological well-being of people living with HIV/AIDS under the new epidemic characteristics in China and the risk factors: a population based study. International Journal of Infectious Diseases 28: 147-152, 1201-9712/ß 2014 the authors published by Elsevier Ltd.

Wig, N., Lekshmi, R., Pal, H., Ahuja, V., Mittal, C. M., Agarwal, S. K. (2006). The impact of HIV/AIDS on the quality of life: A cross sectional study in north India. Indian Journal of Medical Sciences 2006;60: 3-12. 